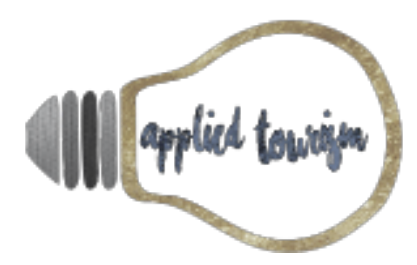

Volume 4, número 1, 2019, p. 57- 77

\title{
DETERMINAÇÃO DE PREVISÕES DE ESTOQUE EM HOTELARIA: cenário vigente em. meios de hospedagem de Barbacena, Tiradentes e Lima Duarte (Conceição Do Ibitipoca)
}

\author{
Luciano Alves Nascimento \\ Doutorando em Ciências Empresariais e Sociais (UCES/Buenos Aires) \\ Mestre em Administração e Desenvolvimento Empresarial (UNESA/Rio de Janeiro) \\ Professor na Universidade do Estado de Minas Gerais e na Faculdade SENAC Minas -Barbacena \\ luciano.nascimento@uemg.br / luciano.nascimento@mg.senac.br \\ Leila de Assis Cobuci \\ Mestre em Planejamento e Gestão do Turismo (Universidade de Aveiro/Portugal) \\ Professora na Faculdade SENAC Minas -Barbacena \\ leila.cobuci@mg.senac.br /lcobuci@gmail.com \\ Messias Tadeu Dias de Assis \\ Tecnólogo em Hotelaria (Faculdade SENAC Minas - Barbacena) \\ assismessias805@gmail.com \\ Kauê de Oliveira Pereira \\ Tecnólogo em Hotelaria (Faculdade SENAC Minas -Barbacena \\ kauemonassa507@hotmail.com \\ Bruna de Paula Neto \\ Tecnólogo em Hotelaria (Faculdade SENAC Minas -Barbacena \\ Bruna.neto@gmail.com
}

Recebido: 06 de setembro, 2018

Aprovado: 15 de fevereiro, 2019

\section{RESUMO}

O objetivo principal desta pesquisa foi levantar dados que permitissem delinear o cenário de utilização de metodologias estruturadas de cálculo e obtenção de previsões de demanda de estoques em meios de hospedagem característicos das cidades de Barbacena, Tiradentes e Lima Duarte (restrito ao distrito de Conceição do Ibitipoca), viabilizando o planejamento de ações que pudessem melhorar a qualidade das decisões gerenciais em empreendimentos de hospedagem das regiões alcançadas pela pesquisa. Através da análise dos dados coletados por meio da aplicação de um questionário, buscou-se resposta aos objetivos de pesquisa. Os resultados revelaram um cenário de predomínio de empreendimentos de hospedagem que são pequenos ou de médio porte, com baixo nível de prioridade atribuído às atividades de gerenciamento de estoques, embora lidem frequentemente com faltas de itens, uso muito pouco comum de metodologias estruturadas de cálculo de previsões e com pouca preocupação com os impactos da má gestão dos estoques sobre os resultados do meio de hospedagem.

Palavras-chaves: Previsões. Estoques. Hotelaria. Logística. 


\section{INTRODUÇÃO}

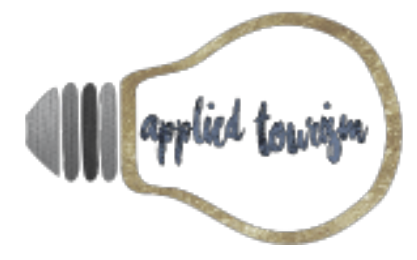

Volume 4, número 1, 2019, p. 57- 77

O mundo tem presenciado, há pouco mais de três décadas, um processo de internacionalização dos mercados dos diversos países, impulsionado pelo movimento dos capitais internacionais e pelo avanço das telecomunicações, entre outros fatores. Nesse processo, o Brasil passou por uma rápida abertura de seus mercados, causando uma transformação profunda na economia e na organização do trabalho.

Desde os primórdios da Administração, gerenciar empresas inclui, muitas vezes, compatibilizar cenários de escassez de recursos com expectativas de altos ganhos ou, como se tem dito ultimamente, fazer mais com menos. Nesta empreitada, as empresas buscam fórmulas criativas, mas sempre que possível, ancoradas em conhecimento científico, para conseguir atingir níveis cada vez mais altos de eficiência e eficácia. Esta máxima, também, se aplica às empresas hoteleiras.

Nos meios de hospedagem, uma das formas mais utilizadas para alcançar eficiência e eficácia envolve planejar estoques de forma a otimizar a relação custo-benefício, seja para o empreendimento, seja para o hóspede. Neste contexto, o estoque agrega valor ao serviço hoteleiro pois, para a prestação do serviço, produtos são consumidos para que o cliente tenha suas necessidades e desejos satisfeitos. Neste sentido, é de se supor que os estoques assumam a forma de diferencial competitivo para as empresas hoteleiras, onde quem mais rápido consegue atender seu cliente, com qualidade e respeitando-se as necessidades de quantidade, no prazo por ele demandado, consegue uma fatia maior do mercado em relação aos concorrentes.

Adicionalmente, segundo Ballou (2010), os estoques conferem segurança para as organizações, pois as mesmas têm neles uma proteção contra as incertezas relacionadas com as flutuações de demanda e com o tempo de entrega, bem como obtêm proteção contra inflação, entre outros ganhos. Nesta mesma perspectiva, Martins e Alt (2006) afirmam que, para as empresas, níveis altos de estoque conferem maior probabilidade de pronto atendimento, pois o não atendimento de um pedido significa prejuízo para a empresa. Pode-se inferir que, no caso da Hotelaria, não ter capacidade de pronto atendimento gera perda de credibilidade e de vendas, difíceis de rever, diferentemente do ocorre em outras áreas, especialmente industriais, em que a margem de manobra é mais flexível.

Por outro lado, tanto Ballou (2010) como Martins e Alt (2006) destacam que se as empresas têm estoques muito altos, eles podem esconder muitos problemas gerenciais, tais como, desperdícios diversos, quebras frequentes de equipamentos, alto turn over, ineficiência do processo produtivo, além de acarretarem custos excessivos que 


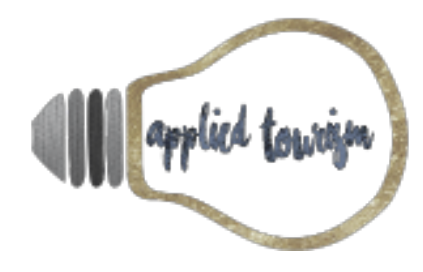

Volume 4, número 1, 2019, p. 57- 77

podem causar prejuízos, inclusive para os hotéis, principalmente em se tratando de produtos perecíveis. A este respeito, o autor afirma que:

Os estoques continuam sendo um grande investimento de capital no canal de suprimentos. Boa gestão significa mantê-los no nível mais baixo possível consistente com o equilíbrio custos diretos e indiretos atribuídos ao seu nível e com a necessidade de manter nível adequado de disponibilidade de produtos (Ballou, 2010, p. 313)

Para evitar perdas, Gonçalves (2007) afirma que é necessário projetar os cursos de ações futuras com base nas estimativas das necessidades de recursos, incluindo o cálculo das previsões entre as atividades de planejamento empresarial. Bouzada e Saliby (2009) reconhecem que a determinação das previsões adquire status de trabalho crítico em relação às atividades que são responsáveis por proporções altas dos custos empresariais e este raciocínio pode e deve ser aplicado para as atividades que consomem estoques e são responsáveis por altas margens de lucro, visando potencializar os ganhos.

Diversos estudos empíricos têm sido feitos por meio de modelos exponenciais para previsão da demanda de materiais de estoque de vários tipos, tais como: peças de veículos, produtos químicos, equipamentos de reparo, produtos alimentícios, peças industriais, militares e agrícolas (Eaves \& Kingsman, 2004); (FAIRFIELD \& KINGSMAN, 1993); (García-Flores, Wang, \& Burgess, 2003); (Gardner Jr. \& Fildes, 1991); (Gardner Jr. \& Joaquin, 2002); (Sani \& Kingsman, 1997); (Snyder, 2002); (Strijbosch, Heuts, \& van der Schoot, 2000); (A. A. Syntetos, Boylan, \& Croston, 2005); (Aris A Syntetos \& Boylan, 2005); (Willemain, Smart, Shockor, \& DeSautels, 1994); (Willemain, Smart, \& Schwarz, 2004).

Na Hotelaria em particular, nota-se uma ausência crônica de preocupação em operar com a determinação de previsões, embora seja possível supor que os estoques sejam um componente de custos significativo, especialmente quando se refere a estabelecimentos com nível de serviço mais elevado, pois, muitos dos diferenciais de atendimento aos clientes dependem dos estoques para serem disponibilizados.

Para Silva e Farias (2015), estabelecer uma política de gerenciamento de estoque nos empreendimentos hoteleiros possibilita um embasamento para justificar a tomada de decisão, na busca do equilíbrio da manutenção de estoque e os custos relacionados a esse. Para as autoras estes processos oportunizam realização de compras de forma mais adequada, no prazo certo e na quantidade necessária, adaptando-se as características de fornecimento. 


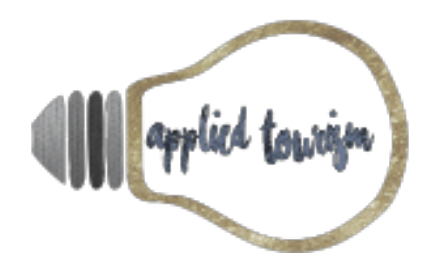

Volume 4, número 1, 2019, p. 57-77

Neste sentido, o dimensionamento dos recursos de estoque em empresas hoteleiras requer o constante conhecimento do comportamento da demanda dos seus materiais, e estimativas futuras dessa demanda, proporcionando uma contribuição importante para o planejamento da produção ou dos serviços prestados. Paralelamente, quando o gerenciamento de um sistema de estoque envolve o controle de milhares de itens, situação comum em grandes indústrias ou em grandes conglomerados de prestação de serviços, a exemplo da Hotelaria, é fácil deduzir que o procedimento de previsão da demanda dos materiais pode se tornar custoso se não houver automatização.

Considerando a importância da temática das previsões em hotéis, o presente projeto teve como objetivo central delinear o perfil de hotéis de pequeno e médio porte nas cidades de Barbacena, Tiradentes e Lima Duarte (restrito à localidade de Conceição do Ibitipoca) quanto ao uso de metodologias estruturadas para a formulação de previsões de estoque, revelando o cenário existente e sinalizando que o uso das ferramentas de previsão representa oportunidade de melhoria na tomada de decisão, considerando que, por meio da análise de dados gerados por métodos formais, os gestores de hotéis e pousadas de Barbacena, Ibitipoca e Tiradentes podem atender melhor os seus clientes, além de ter visão concreta sobre suas preferências e demandas de consumo.

\section{REFERENCIAL TEÓRICO}

Para o desenvolvimento deste artigo torna-se necessário o estudo dos conceitos de previsão da demanda sob a ótica da administração de materiais. Posteriormente, são discutidos os tipos de modelos de previsão e, em seguida, empreendido um aprofundamento específico sobre o método da decomposição clássica, passível de uso em contextos da Hotelaria.

Pode-se dizer com alguma segurança que a previsão de demanda é atividade importante para grande parte das empresas, justamente por ser "a primeira etapa no planejamento de uma cadeia de suprimentos" (Taylor, 2005, p. 193). Ainda, segundo este autor, calcular previsões consiste num exercício de futurologia, mas com o uso das técnicas apropriadas é possível fazer com que meros palpites estejam o mais próximo possível da realidade. Chopra e Meindl (2006) têm entendimento semelhante, lembrando que todas as decisões da cadeia de suprimento são baseadas em uma estimativa de demanda futura. Ballou ( 2010) reforça a teoria de que as previsões são importantes na medida em que admite que o planejamento e controle das atividades logísticas dependem de estimativas acuradas dos volumes de produtos e serviços que serão demandados pelo mercado. 


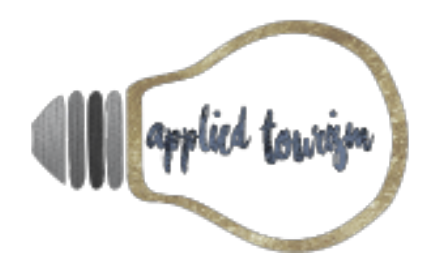

Volume 4, número 1, 2019, p. 57- 77

Em síntese, os grandes autores do campo da logística e dos estudos de métodos de apoio à decisão veem no cálculo das previsões o primeiro passo nas operações das cadeias de suprimentos, atribuindo-lhe grande importância no aumento do desempenho empresarial.

A determinação de uma previsão quase sempre está vinculada à necessidade de se tomar uma decisão (Moore \& Weatherford, 2005), isto é, calcula-se uma previsão com o objetivo de apoiar a escolha de uma ou mais alternativas a seguir. Bouzada e Saliby (2009) enfatizam que o aumento da competitividade entre as organizações acentua a busca por melhorias no processo de tomada de decisão para otimizar a alocação de recursos empresariais escassos para diversas atividades concorrentes.

Em teoria, existem diversos métodos para cálculo de previsões e eles são utilizados em consonância com a natureza do problema cujo comportamento se deseja prever, conforme afirma Ballou (2010). O mesmo autor, propõe ainda que quando o grau de incerteza da variável a ser prevista é muito alto, a ponto de as ferramentas mais tradicionais se mostrarem ineficazes, torna-se conveniente o uso de abordagens mais contemporâneas para determinação da previsão.

A previsão da demanda representa um dado fundamental para o planejamento empresarial, permitindo dimensionar adequadamente os recursos necessários à empresa (Makridakis, Wheelwright, \& Hyndman, 1998). Os gerentes não podem planejar e controlar a capacidade produtiva sem uma estimativa da demanda, o que torna importante o entendimento quanto aos procedimentos para as previsões de demanda (SLACK, CHAMBERS, \& JOHNSTON, 2002).

Uma previsão pode ser feita de forma qualitativa ou quantitativa. O método qualitativo é subjetivo e baseia-se na intuição e nos julgamentos de peritos ou grupo de pessoas, sendo utilizado quando há pouca ou nenhuma disponibilidade de dados. O método quantitativo baseia-se na análise dos dados históricos, sendo utilizado, portanto, quando há disponibilidade de dados (LEVINE, STEPHAN, KREHBIEL, \& BERENSON, 2005); (Makridakis et al., 1998); (Morettin \& Toloi, 2006).

Bowersox et al. (2013), Ballou (2010) e Moore e Weatherford (2005) dividem as técnicas de previsão em três grandes categorias: Qualitativas, Séries Temporais e Causais. As técnicas qualitativas são indicadas para cenários em que há pouca informação e pouca necessidade de dados históricos em contraste com grande necessidade de avaliação administrativa e consenso, isto é, grande subjetividade. Já o grupo das Séries Temporais compreende os métodos que se utilizam de ferramental estatístico e contam com grande quantidade de dados históricos armazenados, capazes de mensurar com grande objetividade. Por fim, os métodos causais, buscam identificar 


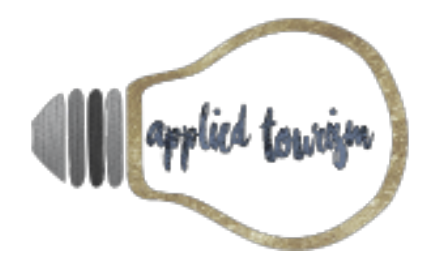

Volume 4, número 1, 2019, p. 57- 77

relações ocultas (ou não percebidas) entre variáveis, por exemplo, consumo e preço, de forma a encontrar em que medida uma variável interfere no comportamento da outra. Compreendendo como ocorrem essas interferências, e em que medida se materializam, é possível determinar previsões.

Chopra e Meindl (2006) ainda destacam um quarto grupo de técnicas de previsão que é a Simulação, nesta classificação constam os modelos que se baseiam em reproduzir escolhas dos consumidores que geram a demanda para, a partir de então, determinar uma previsão ou conjunto de previsões. Segundo os autores, a grande vantagem deste tipo de modelo é a possibilidade de combinar diferentes técnicas para responder a questões complexas ligadas à determinação da previsão, tais como, "qual será o impacto de uma liquidação de preços?" ou "o que pode acontecer com a demanda de nossa empresa se um concorrente abrir uma filial na mesma rua?" etc.

O método quantitativo de previsão pode ser analisado de duas formas. A primeira relaciona a variável demanda com outras variáveis por meio de causalidades, em geral previstas pela teoria econômica, por exemplo a demanda como uma função do preço e da renda. Neste caso, os modelos econométricos são elaborados para o cálculo da previsão da demanda. A segunda forma analisa apenas o histórico da variável demanda, sendo o seu comportamento passado utilizado para estimar o seu comportamento futuro, por meio de modelos de séries temporais (LEVINE et al., 2005); (Makridakis et al., 1998); (Morettin \& Toloi, 2006); (Makridakis et al., 1998); (Pindyck \& Rubinfeld, 2004).

Para Morettin e Toloi (2006, p. 1), "uma série temporal é qualquer conjunto de observações ordenadas no tempo", conceito similar define uma série temporal como "um grupo de observações de uma variável no tempo" (MONKS, 1987, p. 198). Este mesmo autor conceitua ainda dois importantes componentes de uma série temporal, que são abordados neste trabalho: tendência e sazonalidade. A tendência pode ser definida como a inclinação, positiva ou negativa, dos dados no tempo, e a sazonalidade como variações cíclicas e similares em períodos determinados.

Os modelos de previsão de séries temporais podem ser entendidos como procedimentos para projeção futura de um dado, por meio do seu próprio comportamento passado (Makridakis et al., 1998); (Pindyck \& Rubinfeld, 2004); (LEVINE et al., 2005).

Uma síntese expositiva dos modelos de previsão mais utilizados, obtidos por meio de séries temporais, pode ser encontrada em Monks (1987), conforme apresentado na Tabela 1: 


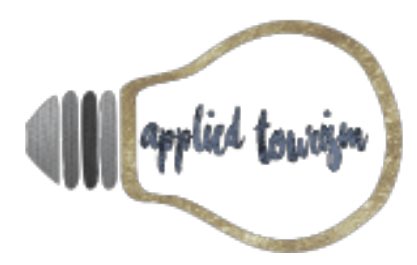

Volume 4, número 1, 2019, p. 57- 77

Tabela 1 - Resumo dos métodos de previsão - Séries de tempo - QUANTITATIVA

\begin{tabular}{|l|l|}
\hline Método & Descrição: \\
\hline Ingênuo & $\begin{array}{l}\text { Usa a regra simples de que a previsão iguala o último valor ou o último acrescido de um } \\
\text { fator de correção. }\end{array}$ \\
\hline Média móvel & A previsão é a média dos $n$ períodos mais recentes. \\
\hline Projeção de tendência & A previsão é linear, exponencial, ou outra projeção de tendência passada. \\
\hline Decomposição & $\begin{array}{l}\text { A série de tempo é dividida em componentes de tendência, periódicos, cíclicos e } \\
\text { aleatórios. }\end{array}$ \\
\hline Ajuste exponencial & $\begin{array}{l}\text { A previsão é uma média móvel ponderada exponencialmente, na qual os dados mais } \\
\text { recentes têm maior peso. }\end{array}$ \\
\hline Box-Jenkins & $\begin{array}{l}\text { Um modelo de regressão de série de tempo é proposto, testado estatisticamente, } \\
\text { modificado e novamente testado até ficar satisfatório. }\end{array}$ \\
\hline
\end{tabular}

Fonte: (MONKS, 1987, p. 197).

Este artigo desenvolveu uma revisão dos métodos de previsão e, mais especificamente, do método da decomposição clássica, que é o procedimento mais indicado quando se requer previsões para sistemas de estoque com poucos itens, como parece ser o caso das empresas hoteleiras.

\section{Métodos de Previsão de Séries Temporais}

Conforme Moore e Weatherford (2005), sempre que se tem um conjunto de valores para uma única variável de interesse, cronologicamente organizado, e que permite projetar o comportamento da variável ao longo do tempo, está-se diante de uma série temporal.

Existem diversas técnicas para se estudar séries temporais a fim de determinar previsões e, entre elas, destaca-se a Decomposição Clássica.

\section{Decomposição Clássica}

Segundo Bouzada e Saliby (2009), a Decomposição Clássica consiste num modelo univariado, isto é, focado no comportamento de uma única variável de interesse, que disseca a série temporal, isolando os componentes mais simples que a compõem, tais como tendência, ciclo, sazonalidade e variações irregulares. Ao final da aplicação do modelo, tem-se a medida objetiva de cada um dos componentes na formação da série histórica e, com isto, é possível elaborar modelos de previsão mais eficazes.

Ballou ( 2010) destaca que a Decomposição Clássica é caracterizada pela simplicidade matemática e grande difusão no meio científico, além disto, enfatiza que nenhum método mais sofisticado conseguiu gerar precisão muito superior a ela. Em contraponto, Calôba, Calôba e Saliby (2002) realizaram um estudo que concluiu que, no caso em questão, o uso combinado de Decomposição Clássica com Redes Neurais Artificiais gerou resultados 


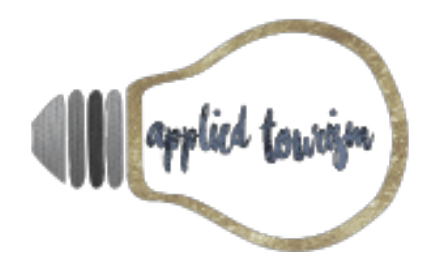

Volume 4, número 1, 2019, p. 57- 77

superiores ao uso das referidas técnicas isoladamente, chegando a afirmar que a redução dos fatores aleatórios se citou em torno de $10 \%$, o que consideraram significativo.

Geralmente, a Decomposição Clássica emprega raciocínios matemáticos pouco complexos (BOUZADA e SALIBY, 2009) para decompor a série histórica, demonstrando seus elementos constituintes, a saber:

Sazonalidade: refere-se a oscilações de curto ou médio prazo que afetam o comportamento da demanda dentro de um lapso de tempo (ano, mês, quinzena, semana etc) que é considerado para determinação da previsão. Conforme Bouzada e Saliby (2009) e Ballou ( 2010), consiste em oscilações que obedecem a um padrão quase idêntico e que ocorrem, geralmente, em períodos fixos ao longo do parâmetro de tempo que é considerado para estudo das previsões.

Ciclo: Correspondem a flutuações de longo prazo e que se distribuem ao longo da linha de tendência da série temporal. Normalmente, é influenciado por ondas de expansão ou retração econômica, bem como outros fatores que causam impacto por longo tempo.

Tendência: consiste numa influência de longo prazo que faz com que a série histórica tenha evolução (aumento), estabilidade ou involução (diminuição) de valores sistemática e continuamente. Normalmente, a tendência é afetada por variáveis conjunturais, tais como aumento ou diminuição de população, nível de desenvolvimento tecnológico, mudanças na aceitação dos produtos da empresa etc.

Erro ou Variações Irregulares: correspondem a variações no nível de demanda que não são justificadas pelos outros componentes da série histórica.

O objetivo de identificar e mensurar cada um desses componentes de uma série histórica é detectar padrões de comportamento em cada um desses componentes, visando permitir o exercício de previsões. Conforme enfatizam Bouzada e Saliby (2009), "sem identificar um padrão de comportamento, fica muito difícil, por exemplo, fazer um exercício de previsão acerca do futuro da grandeza".

\section{METODOLOGIA}

A presente pesquisa é tem caráter descritivo e explicativo. Malhotra (2012) afirma que pesquisa descritiva é aquela que identifica e apresenta características de determinada população ou amostra. A coleta de dados se deu através de pesquisa de campo, tendo sido utilizado um questionário para levantamento dos dados que fundamentam as conclusões apresentadas neste artigo. 


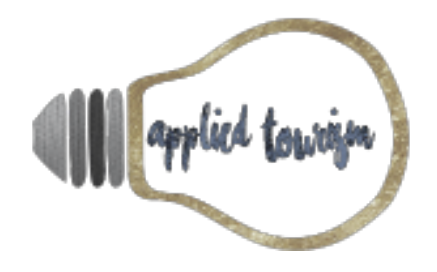

Volume 4, número 1, 2019, p. 57- 77

As empresas hoteleiras situadas nas cidades de Barbacena, Lima Duarte (Distrito de Conceição do Ibitipoca) e Tiradentes, todas em Minas Gerais, vinculadas às associações representativas do setor hoteleiro em cada cidade, compuseram a população de onde se extraiu a amostra de meios de hospedagem pesquisados. Tal amostra foi composta a partir da seleção aleatória de 130 meios de hospedagem, visando alcançar os fins propostos pela pesquisa.

A coleta das respostas se deu através da aplicação presencial de questionários. As respostas captadas foram consolidadas e apresentadas usando técnicas de estatística descritiva, evidenciando número total de respondentes, regiões das empresas dos respondentes, porte das empresas dos respondentes e porte dessas empresas.

A análise dos dados contou com emprego de instrumentos de estatística descritiva básicos, visando descrever o perfil dos respondentes no tocante ao porte e localização das empresas hoteleiras alcançadas pela pesquisa. $\mathrm{Na}$ sequência, promoveu-se a tabulação das respostas às questões relacionadas com a adoção e uso de metodologias estruturadas de cálculo de previsões de estoques.

Segundo Malhotra (2012), dificuldade típica dos questionários é que os respondentes alcançados pela pesquisa podem ser incapazes de prover as respostas que lhe são solicitadas ou mesmo podem apresentar, de alguma forma, relutância em conceder as informações desejadas pelos pesquisadores. De forma complementar, Roesch, Becker e Mello (2005) destaca que os respondentes podem não compreender com clareza o enunciado das perguntas, o que produziria respostas distorcidas ou inválidas. No caso de questões direcionadas à compreensão de modos de agir ou de julgar, Easterby-Smith, Thorpe e Lowe (1999) sinalizam que podem surgir limitações importantes porque, muitas vezes, os respondentes não sabem informar o porquê de suas ações e que tipo de ideia embasa seus julgamentos.

Além das limitações próprias do método de coleta e tratamento de dados, cabe indicar que, por se tratar de uma pesquisa baseada em amostragem do tipo não probabilístico, não é possível propor generalizações.

Outro aspecto a ponderar, no tocante às limitações da pesquisa, é sobre a sinceridade, que pode interferir no resultado final. Isto decorre do fato de que a coleta de respostas está diretamente relacionada à idoneidade da informação apresentada pelos respondentes. 


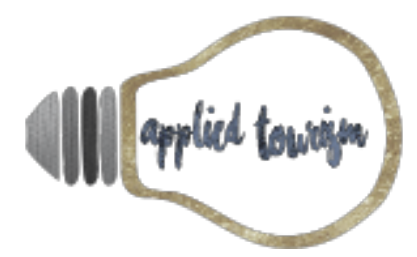

Volume 4, número 1, 2019, p. 57- 77

Ainda, é possível ocorrer o chamado viés de não resposta que é quando se identifica diferenças de avaliação e/ou julgamento entre os respondentes que optam por apresentar respostas, participando da pesquisa e aqueles respondentes que, simplesmente, optam por não responder aos questionários.

Por fim, é importante destacar que, considerando uma suposição de que nem todas as empresas que poderiam ser consideradas relevantes para melhorar a qualidade e o alcance das conclusões desta pesquisa estão vinculadas a associações representativas do setor de hotelaria em suas cidades, tem-se a limitação denominada viés de não convite.

\section{APRESENTAÇÃO E ANÁLISE DOS RESULTADOS}

Considerando os objetivos da pesquisa, seguem abaixo informações que sintetizam o que foi encontrado através do levantamento, levando em conta a baixa adesão por parte dos entrevistados. Menos de 20\% da amostra pretendida aderiu ao questionário, sinalizando que em hotelaria há uma baixa disponibilidade para participação em pesquisas acadêmicas. Fato este que pode e deve ser explorado em futuras pesquisas.

Conforme a Figura 1, abaixo, dos 21 empreendimentos hoteleiros onde foi realizada a pesquisa, Barbacena representa 14\% do grupo, Conceição do Ibitipoca (Lima Duarte) 24\% e Tiradentes 62\% dos respondentes.

Figura 1 - Cidade dos Respondentes

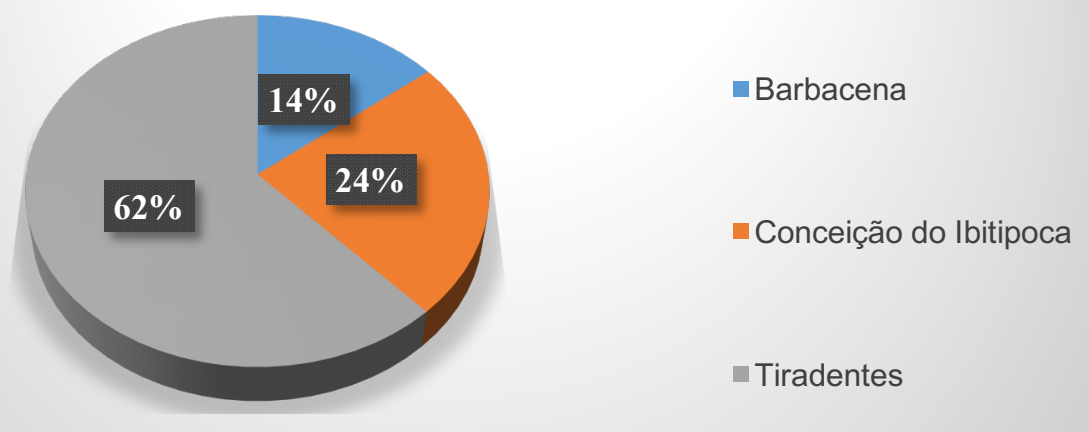

Fonte: Elaborado pelos autores

Avaliando os dados do primeiro gráfico, pode-se ver um certo predomínio de entrevistados na cidade de Tiradentes. Considerando as características do setor hoteleiro em cada região alcançada pela pesquisa, pode-se considerar o resultado como esperado. Embora Barbacena seja uma cidade relativamente maior, 


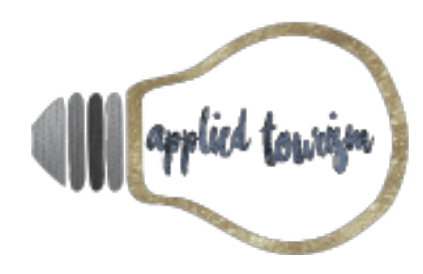

Volume 4, número 1, 2019, p. 57- 77

comparativamente às outras pesquisadas, a efervescência cultural, histórica e turística dos demais locais é bem mais pronunciada.

De acordo com as características dos meios de hospedagem identificadas através da pesquisa, conforme Figuras 2, 3 e 4, conclui-se que são empresas de médio e pequeno porte (28\% possuem até 10 UH's, 29\% entre 11 e 20 UH's e acima de 21 UH's 43\%). Sendo assim, ao questionar como o gestor consegue chegar à quantidade necessária de produtos a serem adquiridos pela empresa, observa-se que não há um controle satisfatório realizado nas dependências do hotel, visto que não descrevem nenhum método de cálculo para indicar a quantidade a ser comprada (concluiu-se que os controles não são satisfatórios, pois, em outra questão, 48\% dos empreendimentos alegaram sofrer com a falta de itens de estoques).

Os procedimentos utilizados são, na maior parte, "compra por demanda" (38\%), (alegando que as aquisições são feitas em função da quantidade de hóspedes) e, em seguida, "compra de acordo com o que acaba" (29\%). Para justificar essas práticas, a maioria dos meios de hospedagem argumentaram que tais práticas são decorrentes da sazonalidade presente nestas localidades, que se caracterizam por demandas em momentos bastante específicos do ano (62\% referem-se aos feriados, eventos locais, férias e período de estação) o que de certa forma afeta o raciocínio por eles aplicado (os gestores dos meios de hospedagem).

Figura 2 - No de UH's disponíveis

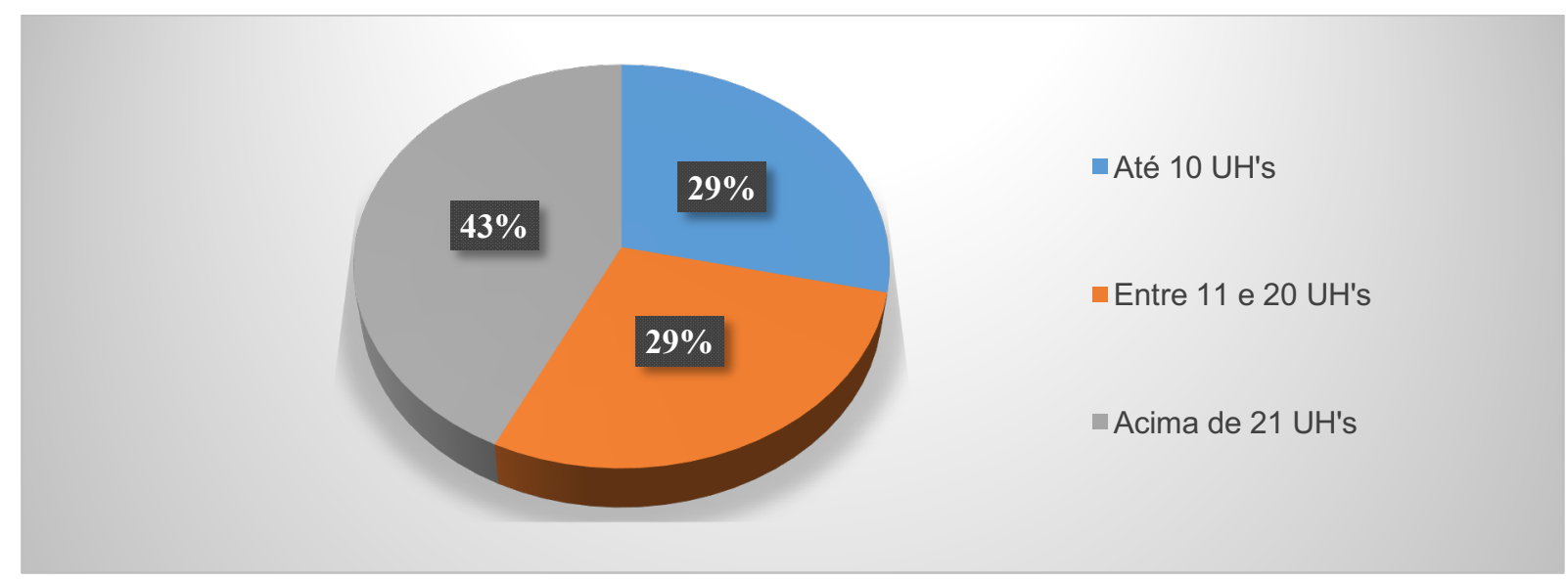

Fonte: Elaborado pelos autores 


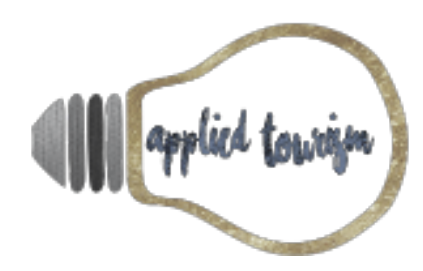

Volume 4, número 1, 2019, p. 57- 77

Figura 3 - Formas de cálculo das quantidades a serem compradas

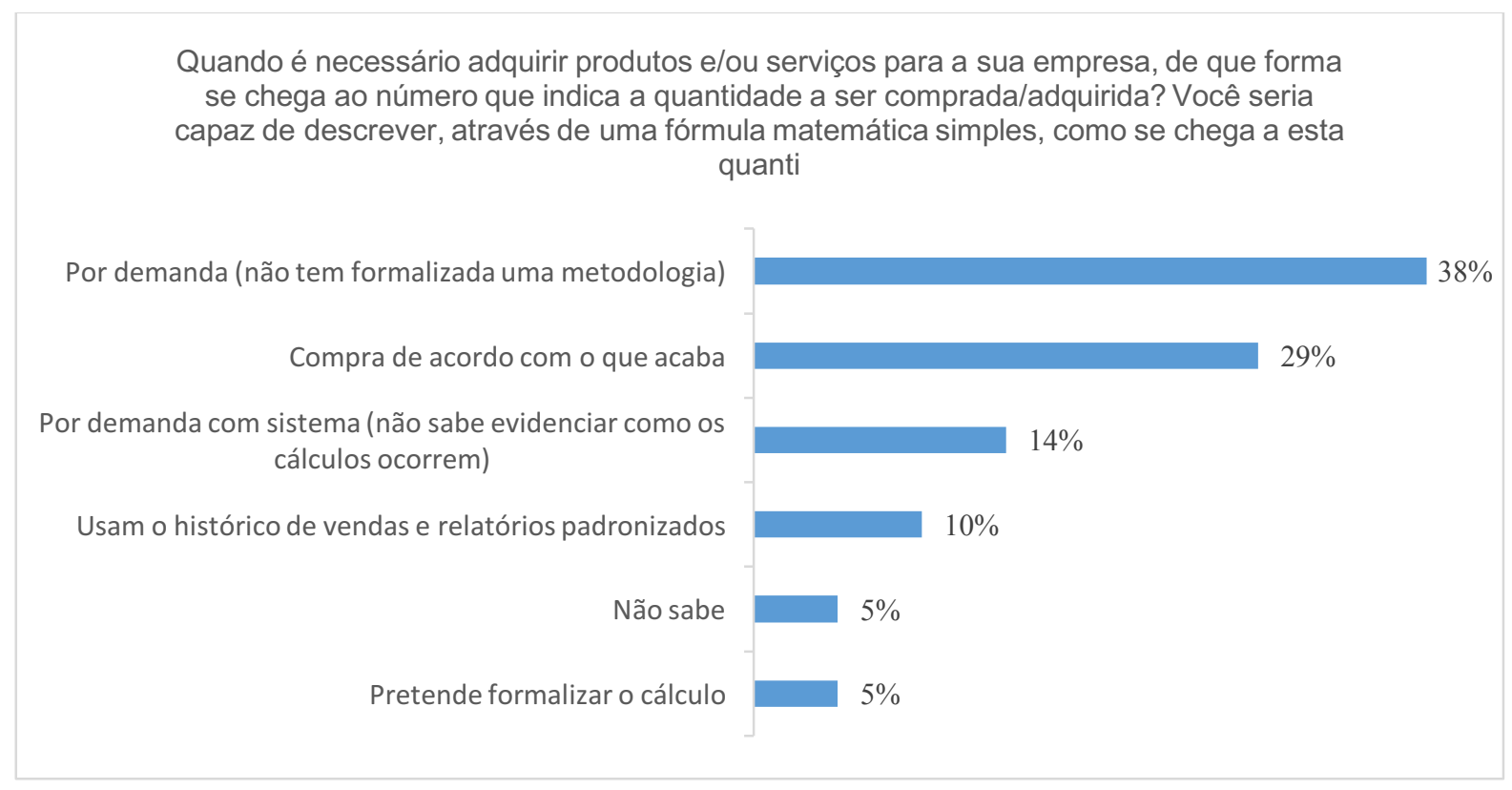

Fonte: Elaborado pelos autores

Figura 4 - Momentos em que o raciocínio de cálculo não funciona

Há algum momento do ano ou do mês em que esse raciocínio não se aplica/ Se sim, de que forma "essa fórmula" ou raciocínio podem ser ajustados?

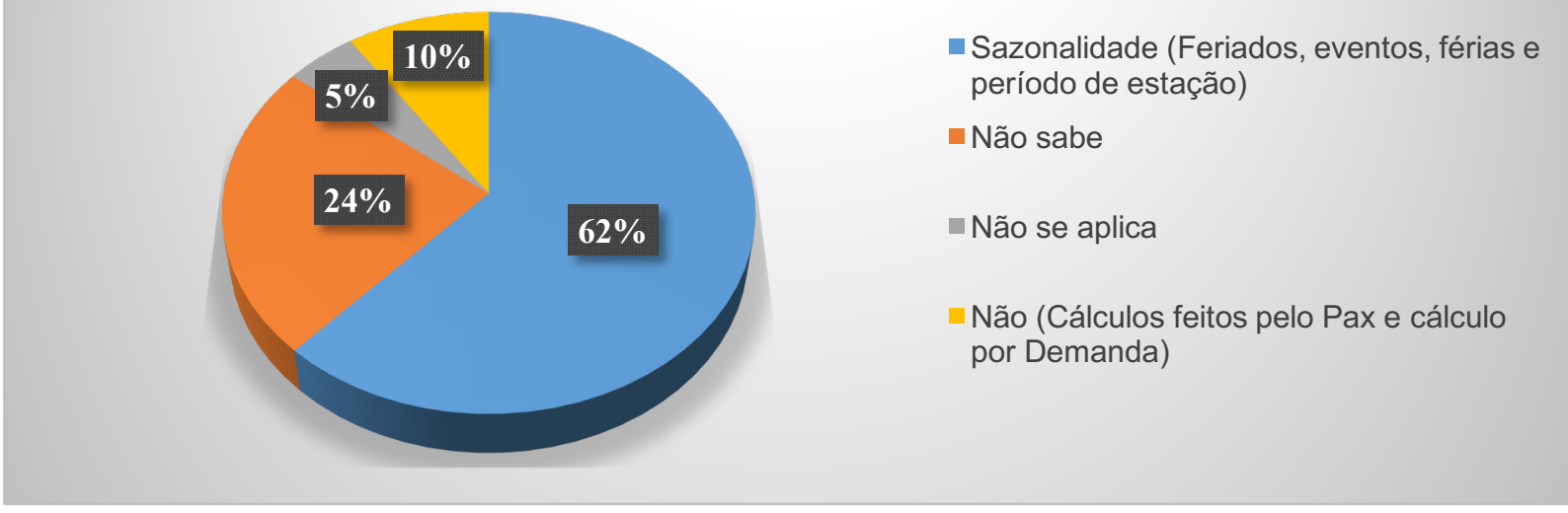

Fonte: Elaborado pelos autores 


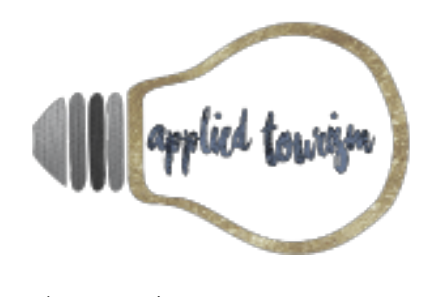

Figura 5-Ocorrências de falta de estoque no meio de hospedagem

Já ocorreu alguma situação que gerou falta de estoque na sua empresa?

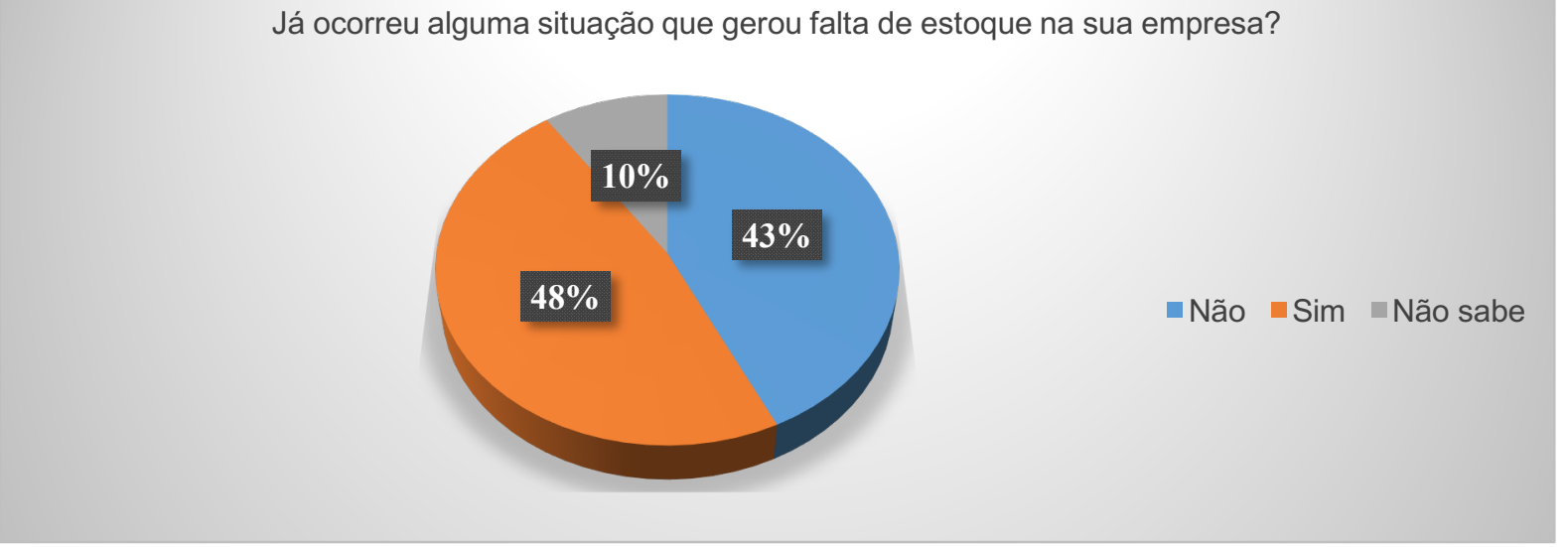

Fonte: Elaborado pelos autores

Ao indagar aos respondentes com que frequência as previsões são calculadas, 67\% afirmam que são realizadas semanalmente, comprando o que é de uso contínuo dentro do meio de hospedagem, conforme visto na figura 6. De maneira complementar se torna conveniente compreender como a relação entre empresa/fornecedor afeta o meio de hospedagem, assim, ao inquirir os gestores se já haviam ocorrido situações em que houve falta de estoque em seu estabelecimento, vide Figura 5, 43\% dos estabelecimentos alegaram que nunca houve falha no estoque, enquanto 48\% deles admitiram ter que lidar com faltas (mas alegaram que é devido a atrasos de fornecedores e não vêm relação com possível ineficiência interna do estabelecimento quando da formulação de previsões).

Como mostra o gráfico 6, abaixo, por haver um predomínio da geração de previsões com periodicidade semanal. Há ainda um montante relevante de empreendimentos que geram previsões diariamente (5\%) e outro quantitativo, ainda maior, de 10\%, que alegam não saber que periodicidade empregam. Pelas opções de respostas que emergiram diante desta questão, que foi aberta, é possível presumir que há ausência de critérios mais maduros para a lida com a questão das previsões, pois as vantagens previstas na teoria para as compras realizadas de forma planejada, claramente, deixam de ser colhidas diante do cenário de cálculo de previsões revelado pela pesquisa. Elementos que apoiam esta constatação podem ser encontrados nas análises dos gráficos das questões 7 e 8.

Para os meios de hospedagem que alegaram ter alguma metodologia mais estruturada para o cálculo e/ou obtenção de previsões, foram apresentados outros questionamentos, cujos resultados podem ser conferidos nos 


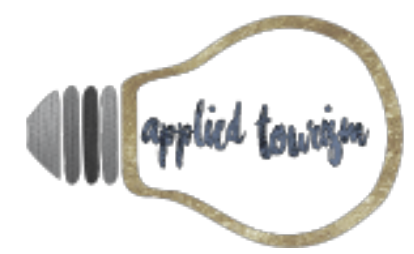

Volume 4, número 1, 2019, p. 57- 77

gráficos das figuras 7 e 8 , visando oferecer uma melhor compreensão de como os gestores planejam a aquisição de insumos. Quando inquiridos quanto ao tipo de metodologia utilizada na organização para obtenção de previsões, 48\% dos respondentes mencionaram o uso de planilhas e alguns sistemas hoteleiros, já 38\% dos respondentes, um número relativamente alto, declararam que operam através de controles manuais, reforçando a percepção de que, ainda nos dias de hoje, mesmo com todos os avanços tecnológicos disponíveis, muitos hotéis ainda não aplicam sistemas que são capazes de gerar resultados mais precisos. Ao serem questionados se há algum tipo de dificuldade para que sejam obtidas informações necessárias para a elaboração de previsões de estoques, 76\% dizem que, por se caracterizarem como um meio de hospedagem pequeno, é possível ter um controle eficiente através apenas de sua experiência empírica no empreendimento. Outros 14\% afirmaram enfrentar algumas complicações para obter tais informações, justificando isto em relação à falta de controle quanto ao que é consumido.

Mesmo quando é alegado o uso de alguma forma de sistema, e ainda mais usando o controle apenas manual, não foi possível identificar o uso de relatórios próprios para a avaliação e compreensão da demanda por estoque nos diversos empreendimentos alcançados pela pesquisa. Essa constatação pode até soar contraditória em relação ao gráfico da figura 9, pois, houve razoável nível de certeza dos gestores ao listar os momentos do ano em que a demanda por itens de estoque é mais intensa. Entretanto, os dados da figura 9 só confirmam uma certeza em relação aos momentos que caracterizam a alta temporada, podendo sinalizar altos consumos de estoque associados, mas, o fato de terem que lidar com frequência com faltas de estoques, evidencia que em relação aos estoques, trata-se de uma certeza difusa e mesmo indireta, baseada apenas na percepção empírica dos momentos em que o hotel tem mais procura de hóspedes, não sendo suficiente para evidenciar uma acompanhamento de melhor qualidade sobre o perfil da demanda de itens de estoque em si. A alta proporção de empreendimentos que alegaram sofrer com a falta de estoque também sinaliza que o planejamento quanto a este quesito é fraco. 


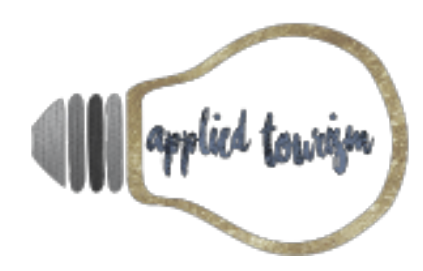

Volume 4, número 1, 2019, p. 57- 77

Figura 6 - Frequência de cálculo de previsões no meio de hospedagem

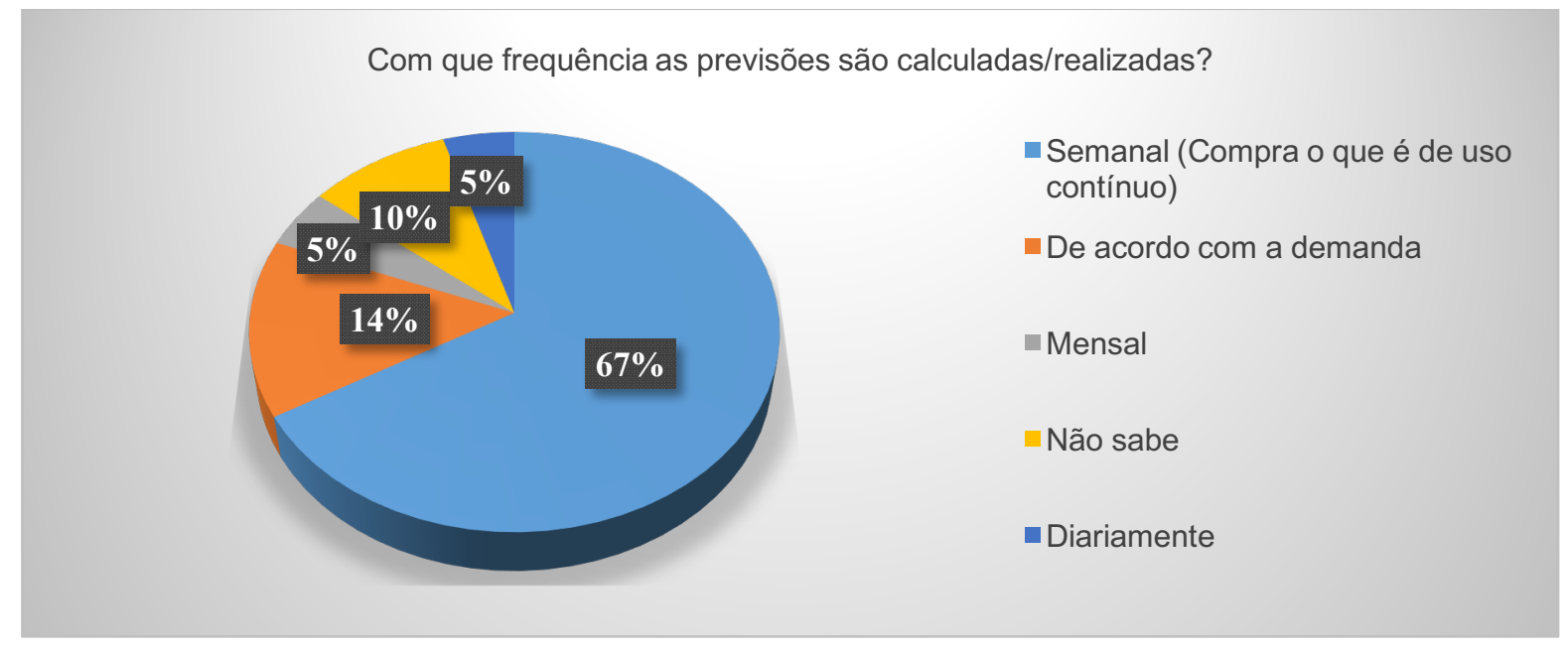

Fonte: Elaborado pelos autores

Figura 7 - Controles que apoiam o cálculo das previsões

Caso a sua empresa tenha uma metodologia própria e sistemática de calcular previsões, de onde ela obtém as informações necessárias à determinação das quantidades que devem ser compradas?

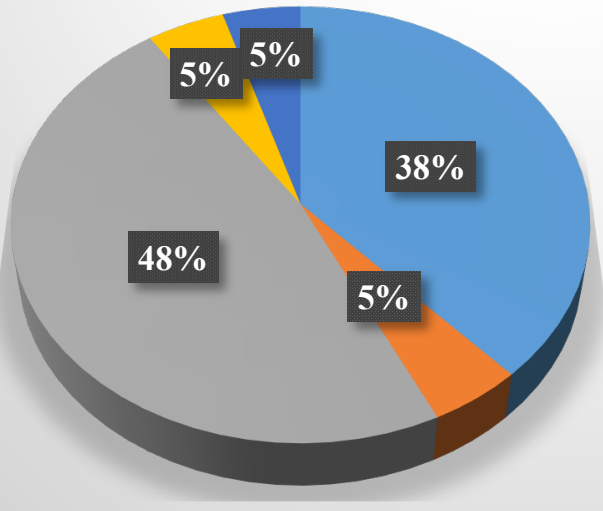

- Controle Manual

Experiência Própria

- Sistemas ( Planilhas no Excel, Desbravador, NetHotel, App Hotel, Eviivo)

Não sabe

Fonte: Elaborado pelos autores 


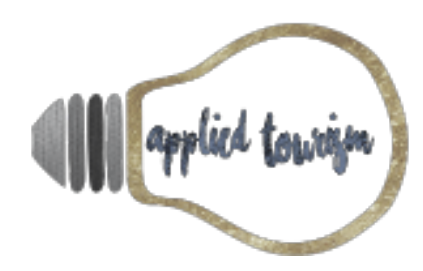

Volume 4, número 1, 2019, p. 57- 77

Figura 8 - Dificuldades na obtenção de informações para cálculo das previsões

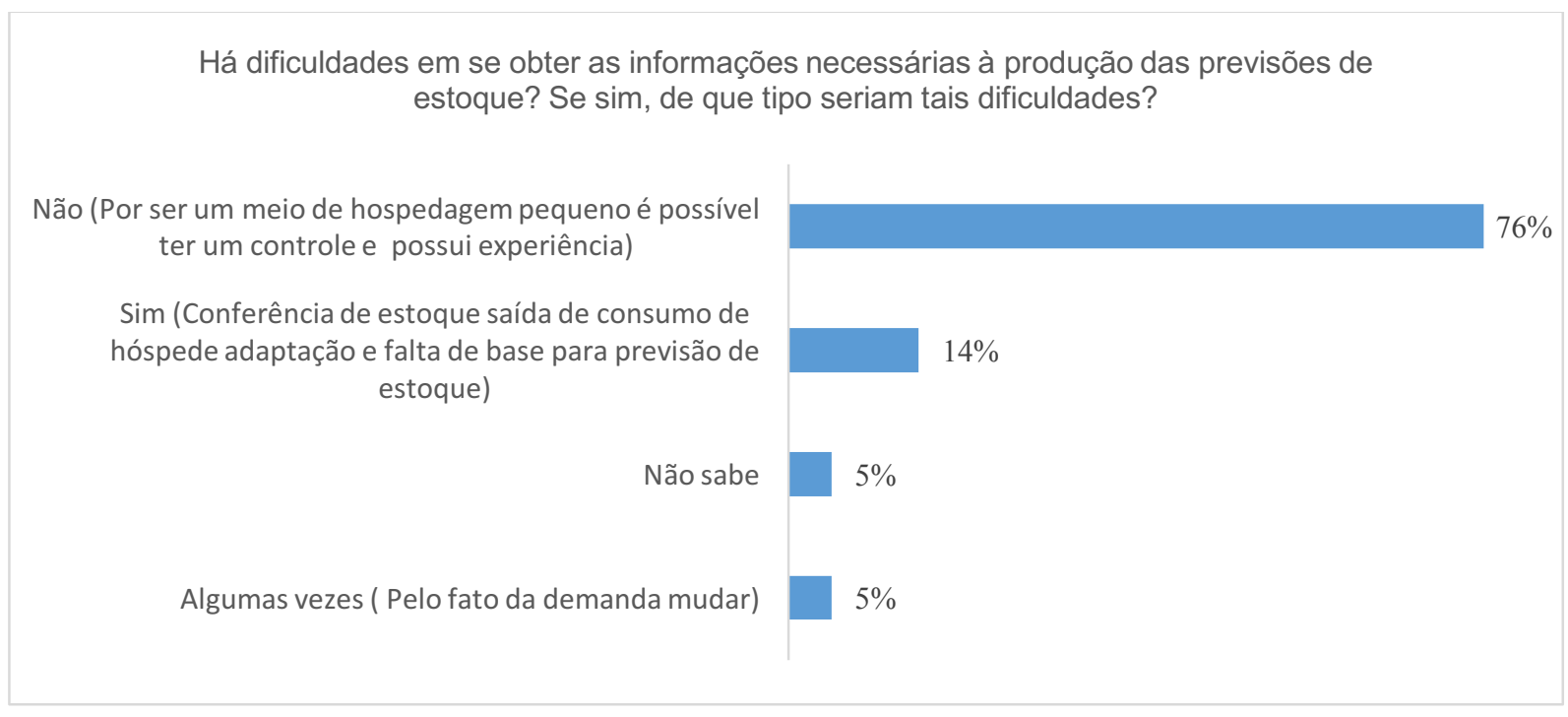

Fonte: Elaborado pelos autores

Figura 9 - Períodos de sazonalidade na demanda por estoques

Os produtos/serviços comprados pela sua empresa têm demanda/consumo regular ao longo do ano ou há períodos em que há mais e menos consumo? Que períodos seriam esses?

Novembro, dezembro e feriados (Carnaval, quaresma, semana santa, inverno e verão)

Depende da demanda (Regular)

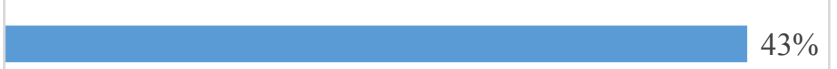

$$
\text { Depende da demanda (Regular) }
$$

Controle feito por Pax
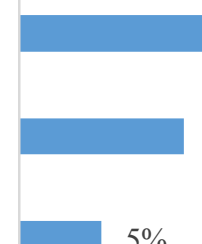

$10 \%$

Setembro e outubro

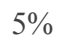

Não sabe

$5 \%$

Fonte: Elaborado pelos autores

Os gestores dos meios de hospedagem alcançados pela pesquisa foram questionados se escolheriam um sistema automatizado ao saber que o mesmo dispõe de diferentes modalidades de cálculos previsões. A este questionamento, $52 \%$ dos respondentes alegaram que este seria um critério importante em sua decisão sobre 


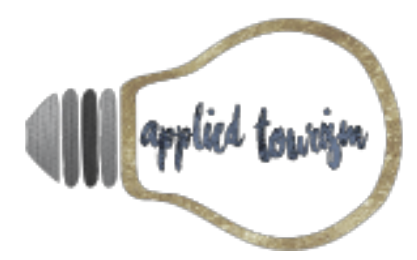

Volume 4, número 1, 2019, p. 57- 77

adoção e implantação de um sistema hoteleiro, enquanto outros 19\% responderam que seriam indiferentes a isso para decidir quanto ao uso de um sistema, pois acreditam que não seria um requisito necessário por serem de um estabelecimento pequeno, como mostra Figura 10.

Figura 10 - Processo de escolha de sistemas para elaboração de previsões

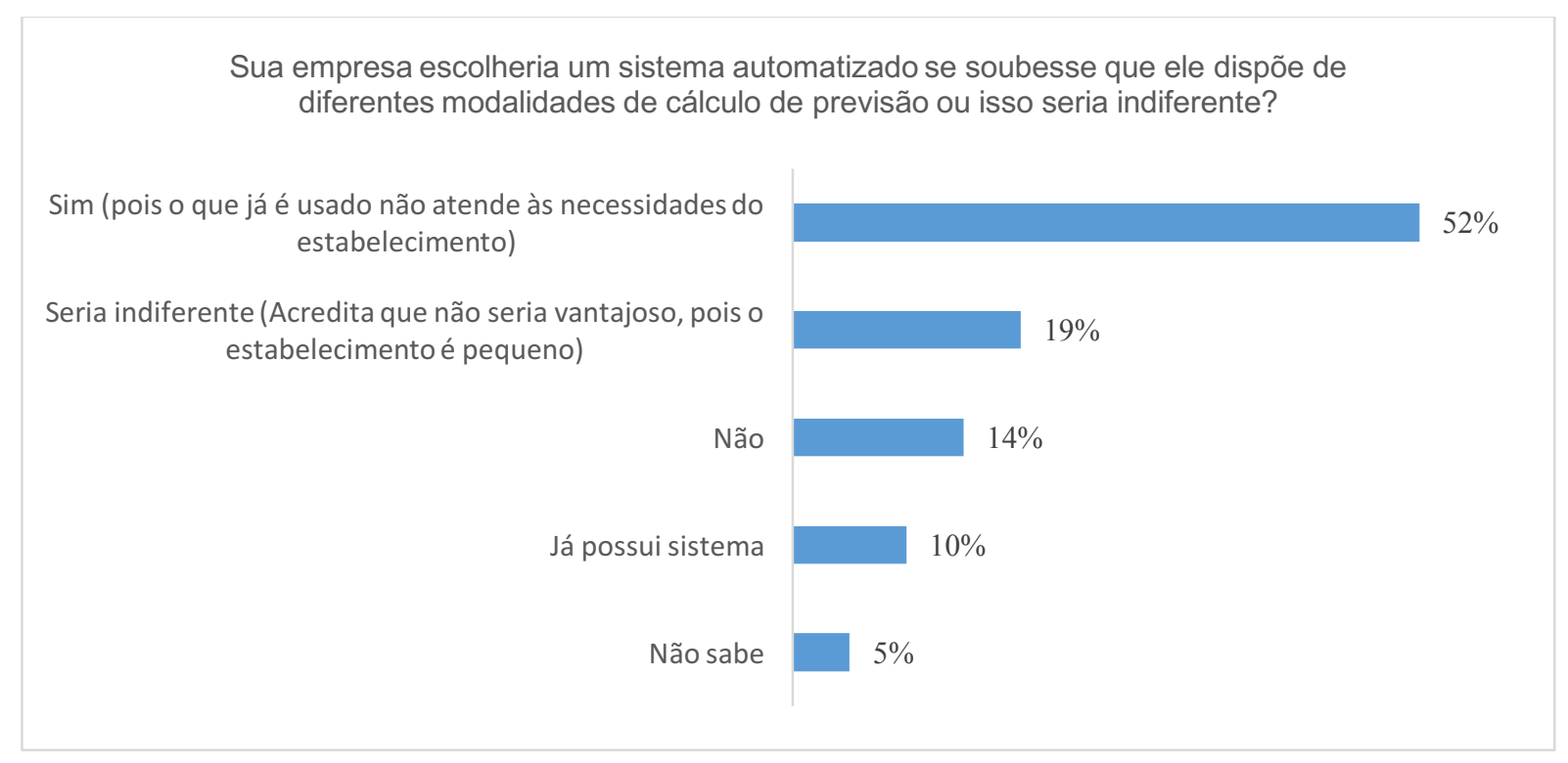

Fonte: Elaborado pelos autores

Em relação às provisões adquiridas e que integram seus estoques, os gestores foram perguntados sobre a existência de algum item sem movimento no último mês. Apenas 33\% disseram que alguns itens do estoque não tiveram movimento no último mês. 10\% afirmaram não saber e outros 10\% afirmaram que esta situação não se aplicaria ao caso deles por não terem grandes volumes estocados. Por fim, 48\% dos respondentes responderam que não teriam itens de estoque sem movimento no último mês, pois tudo o que compram é para consumo imediato. Com base nas impressões colhidas quando da aplicação dos questionários, os pesquisadores não conseguiram formar uma convicção plena de que as respostas apresentadas seriam totalmente verdadeiras, tendo sido perceptível, em muitos casos, notar certo desconforto com a questão por parte dos gestores, pois, ficou aparente falta de controle a este respeito. 


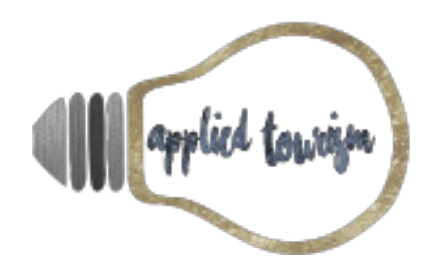

Volume 4, número 1, 2019, p. 57- 77

Figura 11 - Itens de estoque sem movimento no último mês

Atualmente há algum item no seu estoque que não tenha tido movimento no último mês?

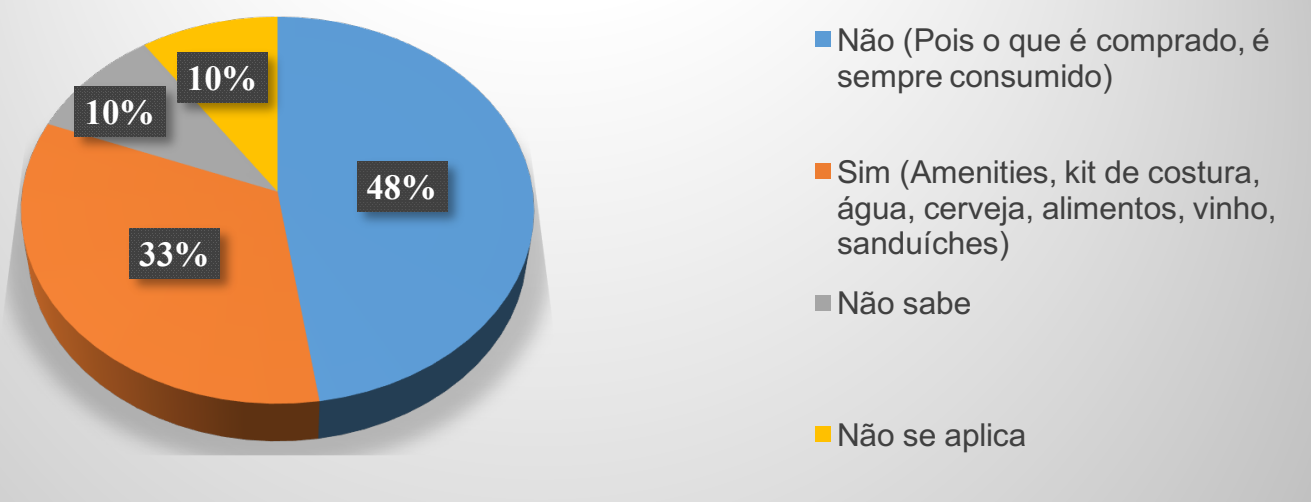

Fonte: Elaborado pelos autores

\section{5- CONSIDERAÇÕES FINAIS}

As empresas em geral, inclusive aquelas do segmento hoteleiro, enfrentam pressões constantes para operar com níveis cada vez mais altos de eficiência e eficácia, pois os recursos de todos os tipos são escassos e seu uso planejamento auxilia no amento de competitividade.

Neste sentido, estruturar formas de compreender o padrão de demanda ou consumo de produtos e serviços, acaba por ser um expediente primordial para redução de custos e obtenção de vantagem competitiva, bem como para buscar maiores níveis de satisfação dos clientes.

A pesquisa realizada para fundamentar as ações do projeto de extensão, sinalizou um cenário promissor em relação ao desenvolvimento e implantação de técnicas mais estruturadas para o cálculo e formulação de metodologias para obtenção de previsões, pois uma parcela muito significativa dos empreendimentos hoteleiros admitiu não ter qualquer abordagem formal para este fim.

Segundo a literatura especializada, tal quadro faz com que ocorram faltas de estoques, conforme pode ser detectado no levantamento inicial e isto pode ocasionar perda de vendas, embora este quesito em particular não tenha sido alvo deste trabalho em particular.

Percebe-se interesse significativo dos meios de hospedagem, mas não necessariamente no tocante a habilidades gerenciais, como seria o caso do controle de estoques e previsões, revelando um cenário em que, talvez, a 


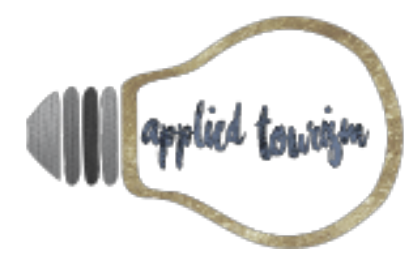

Volume 4, número 1, 2019, p. 57- 77

preocupação com os materiais ainda não teria se tornado prioridade, dado o possível entendimento de que seria uma atividade secundária em relação à hospedagem em si. Esta percepção revela um cenário delicado, pois, notase que os empreendedores a frente de vários meios de hospedagem não conseguem perceber a relação direta entre algumas atividades relacionadas com a gestão de materiais e o efeito sobre o lucro do estabelecimento. Assim, tem-se um terreno fértil para tomadas de decisão equivocadas gerencialmente e, o pior, com grande potencial de gerar insatisfação junto aos clientes que estão cada vez mais exigentes.

Desta forma, a percepção formulada pelos pesquisadores é de que haveria necessidade de explicitar melhor o potencial de redução de custos e aumento de lucros para os meios de hospedagem, evidenciando vantagens que poderiam advir de uma política racional de gerenciamento de estoques e de obtenção de previsões. Este aspecto gerencial teria o condão de reforçar as ações da gestão dos empreendimentos no sentido de buscar ganhos de eficiência e consolidação da eficácia, especialmente, através de melhorias das decisões gerenciais relacionadas com os estoques. Neste sentido, sugere-se a formulação de novas pesquisas que possam ajudar a preencher esta lacuna em particular futuramente

\section{REFERÊNCIAS}

Ballou, R. H. (2010). Gerenciamento da Cadeia de Suprimentos/Logística Empresarial (6 ${ }^{\circ}$ ed). Porto Alegre: Editora Bookman.

Bouzada, M. A. C., \& Saliby, E. (2009). Prevendo a demanda de ligações em um call center por meio de um modelo de Regressão Múltipla. Gestão \& Produção, 16(3), 382-397.

Bowersox, D. J., Closs, D. J., Cooper, M. B., \& Bowersox, J. C. (2013). Gestão logística da cadeia de suprimentos. AMGH Editora.

Calôba, G. M., Calôba, L. P., \& Saliby, E. (2002). Cooperação entre redes neurais artificiais e técnicas' clássicas' para previsão de demanda de uma série de vendas de cerveja na Austrália. Pesquisa Operacional, 22(3), 345-358.

Chopra, S., \& Meindl, P. (2006). Gerenciamento da Cadeia de Suprimentos: Estratégia, Planejamento, e Operação. Gerenciamento da Cadeia de Suprimentos: Estratégia, Planejamento, e Operação. São Paulo: Prentice Hall.

Easterby-Smith, M., Thorpe, R., \& Lowe, A. (1999). Pesquisa Gerencial em Administração: Um guia para monografias, dissertações, pesquisas internas e trabalhos em consultoria. São Paulo: Pioneira.

Eaves, A. H. C., \& Kingsman, B. G. (2004). Forecasting for the ordering and stock-holding of spare parts. Journal of the Operational Research Society, 55(4), 431-437. https://doi.org/10.1057/palgrave.jors.2601697

FAIRFIELD, R. P., \& KINGSMAN, B. G. (1993). Control Theory in Production/Inventory Systems: a case study in a food processing organization. Journal of the Operational Research Society, 44(12), 1173-1182. 


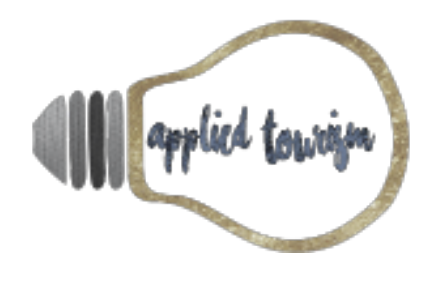

Volume 4, número 1, 2019, p. 57- 77

García-Flores, R., Wang, X. Z., \& Burgess, T. F. (2003). Tuning Inventory Policy Parameters in a Small Chemical Company. The Journal of the Operational Research Society, 54(4), 350-361. Recuperado de http://www.jstor.org/stable/4101704

Gardner Jr., E. S., \& Fildes, R. (1991). Evaluating forecast performance in an inventory control system : Everette S. Gardner Jr., Management Science 36 (1990) 490-499. International Journal of Forecasting, 7(1), 118. https://doi.org/http://dx.doi.org/10.1016/0169-2070(91)90042-T

Gardner Jr., E. S., \& Joaquin, D.-S. (2002). Seasonal adjustment of inventory demand series: a case study, pp. 117123. Share International Journal of Forecasting, 18, 117-123.

Gonçalves, F. (2007). Excel Avançado 2003/2007 Forecast - Análise e Previsão de Demanda. São Paulo: Ciência Moderna.

LEVINE, D. M., STEPHAN, D., KREHBIEL, T. C., \& BERENSON, M. L. (2005). Estatística: teoria e aplicações usando $o$ Excel. ( $5^{\circ}$ ed). Rio de Janeiro: Livros Técnicos e Científicos Editora.

Makridakis, S., Wheelwright, S. C., \& Hyndman, R. J. (1998). Forecasting: methods and applications (3 ${ }^{\circ}$ ed). New York: Editorial JohnWiley \& Sons, Inc.

Malhotra, N. K. (2012). Pesquisa de marketing: uma orientação aplicada (6. ed.). Porto Alegre: Bookman Editora.

Martins, P. G., \& Alt, P. R. C. (2006). Administração de matérias e recursos patrimoniais. Saraiva (2º ed). São Paulo: Saraiva.

MONKS, J. G. (1987). Administração da produção. São Paulo: McGraw-Hill.

Moore, J. H., \& Weatherford, L. R. (2005). Tomada de decisão em administração com planilhas eletrônicas (6. ed.). Porto Alegre: Bookman.

Morettin, P. A., \& Toloi, C. (2006). Análise de séries temporais. (E. Blucher, Org.), Análise de séries temporais. São Paulo.

Pindyck, D. L., \& Rubinfeld, R. S. (2004). Econometria: modelos \& previsões. Rio de Janeiro: Elsevier.

Roesch, S. M. A., Becker, G. V., \& MELLO, M. I. de. (2005). Projetos de estágio e de pesquisa em administração: guia para estágios, trabalhos de conclusão, dissertações e estudos de caso . (3.ed.). São Paulo: Editora Atlas SA.

Sani, B., \& Kingsman, B. G. (1997). Selecting the Best Periodic Inventory Control and Demand Forecasting Methods for Low Demand Items. The Journal of the Operational Research Society, 48(7), 700. https://doi.org/10.2307/3010059

Silva, J. de S., \& Farias, A. P. da S. (2015). O GERENCIAMENTO DE ESTOQUE NUM HOTEL LOCALIZADO NO SERTÃO DE PERNAMBUCO. XI CONGRESSO NACIONAL DE EXCELENNCIA EM GESTÃO. Recuperado de http://www.inovarse.org/sites/default/files/T_15_496.pdf

SLACK, N., CHAMBERS, S., \& JOHNSTON, R. (2002). Administração da produção. São Paulo: Atlas. 


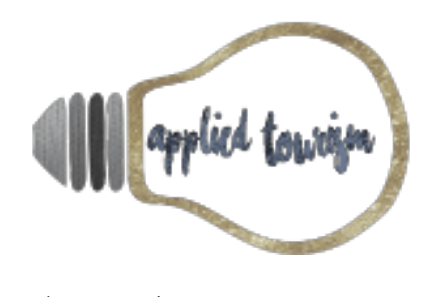

Snyder, R. D. (2002). Forecasting sales of slow and fast moving inventories. European Journal of Operational Research, 140(3), 684-699.

Strijbosch, L. W. G., Heuts, R. M. J., \& van der Schoot, E. H. M. (2000). A combined forecast---inventory control procedure for spare parts. Journal of the Operational Research Society, 51(10), 1184-1192. https://doi.org/10.1057/palgrave.jors.2601013

Syntetos, A. A., \& Boylan, J. (2005). The accuracy of intermittent demand estimates. International Journal of Forecasting, 21(2), 303-314. https://doi.org/10.1016/j.ijforecast.2004.10.001

Syntetos, A. A., Boylan, J. E., \& Croston, J. D. (2005). On the categorization of demand patterns. Journal of the Operational Research Society, 56(5), 495-503. https://doi.org/10.1057/palgrave.jors.2601841

Taylor, D. A. (2005). Logística na cadeia de suprimentos: uma perspectiva gerencial. Rio de Janeiro: AddisonWesley. Recuperado de https://books.google.com/books?id=HwpMNQAACAAJ\&pgis=1

Willemain, T. R., Smart, C. N., \& Schwarz, H. F. (2004). A new approach to forecasting intermittent demand for service parts inventories. International Journal of Forecasting, 20(3), 375-387. https://doi.org/10.1016/S0169-2070(03)00013-X

Willemain, T. R., Smart, C. N., Shockor, J. H., \& DeSautels, P. A. (1994). Forecasting intermittent demand in manufacturing: a comparative evaluation of Croston's method. International Journal of Forecasting, 10(4), 529-538. https://doi.org/10.1016/0169-2070(94)90021-3 